\title{
Desafios da prevenção e controle da dengue na fronteira Brasil/Bolívia: representaçóes sociais de gestores e profissionais da saúde
}

\author{
| ${ }^{1}$ Elisângela Martins da Silva Costa, ${ }^{2}$ Edgar Aparecido da Costa, \\ ${ }^{3}$ Rivaldo Venâncio da Cunha I
}

Resumo: Este estudo tem por objetivo identificar e analisar as representaçôes sociais dos gestores e profissionais da saúde sobre os desafios da prevenção e controle da dengue em Corumbá, Mato Grosso do Sul, fronteira Brasil/Bolívia. Trata-se de uma pesquisa qualitativa fundamentada na teoria das representaçôes sociais. Para a coleta de dados foram entrevistados cinco gestores e 63 profissionais da saúde atuantes na estratégia Saúde da Família e na Santa Casa de Misericórdia de Corumbá; a análise do conteúdo se fez pela técnica do Discurso do Sujeito Coletivo. Os resultados apontam que o município possui grandes dificuldades de enfrentamento da dengue pelo fato de ficar na fronteira. $\mathrm{Na}$ análise dos discursos foram identificadas quatro ideias centrais: insuficiência de recursos financeiros, mobilidade transfronteiriça, reduzida cooperaçáo fronteiriça e cultura dos bolivianos. $\mathrm{O}$ estudo reforça a necessidade de cooperação bilateral ou multilateral para melhor atendimento à saúde nos territórios de fronteira.

> Palavras-chave: dengue; prevenção e controle; áreas de fronteira; profissional de saúde; gestor de saúde.

\author{
1 Universidade Federal de Mato \\ Grosso do Sul. Campo Grande- \\ MS, Brasil (elisams10@gmail.com). \\ ORCID: 0000-0001-8522-8511 \\ ${ }^{2}$ Universidade Federal de Mato \\ Grosso do Sul. Corumbá-MS, \\ Brasil (edgarac10@gmail.com). \\ ORCID: 0000-0002-0043-2642 \\ ${ }^{3}$ Universidade Federal de Mato \\ Grosso do Sul. Campo Grande- \\ MS, Brasil (rivaldo_venancio@uol. \\ com.br). \\ ORCID: 0000-0002-6622-7043
}

Recebido em: 09/09/2017

Aprovado em: 22/06/2018 Revisado em: 08/10/2018 


\section{Introdução}

A dengue é um dos principais problemas de saúde pública no mundo e uma das mais importantes arboviroses que atingem o homem. Estima-se que 390 milhóes de infecçôes ocorram anualmente e mais de $70 \%$ da população mundial estão em risco de contrair a doença (BHATT et al., 2013). No continente americano, em 2016, foram notificados mais de 2,3 milhóes de casos da doença, com 4.274 casos graves e 1.032 mortes (WHO, 2017).

No Brasil, a dengue adquiriu importância epidemiológica a partir de 1986, quando a epidemia pelo subtipo DENV-1 ocorrida no Rio de Janeiro se dispersou para os estados do Nordeste, alcançando Sáo Paulo, Minas Gerais e Mato Grosso do Sul (SCHATZMAYR, 2000). Atualmente, a doença ocorre em todos os estados do Brasil de forma continuada, intercalando-se com a ocorrência de epidemias. De 2002 a 2017, foram notificados aproximadamente 11 milhôes de casos no país, destacando-se as recentes epidemias de 2015 e 2016, com 1,6 e 1,5 milhóes de casos, respectivamente. A taxa média de letalidade nesses dois anos foi de 5,5\% (BRASIL, 2017; 2018).

Diante desses números, destaca-se a importância de contar com mais elementos para o planejamento, implementação e avaliação de programas de controle da doença. Nesse sentido, estudos têm sido desenvolvidos considerando o ponto de vista dos atores envolvidos no processo de enfrentamento da dengue, no âmbito local. Um grupo desses trabalhos concentra-se em identificar conhecimentos, atitudes e práticas da população em relação à dengue, os chamados estudos do tipo CAP (ALVES et al., 2016; SANTOS; CABRAL; AUGUSTO, 2011) enquanto outro grupo busca a compreensão mais aprofundada das crenças, representaçóes e dos comportamentos associados à doença através de estudos qualitativos (CARMONA; DONAIRES, 2016; REIS; ANDRADE; CUNHA, 2013).

Para este artigo, realizou-se um estudo qualitativo, tendo como embasamento teórico a Teoria das Representaçôes Sociais (MOSCOVICI, 1981). As representações, como fenômeno, contêm elementos informativos, cognitivos, ideológicos e normativos, que consistem em crenças e valores, atitudes, opinióes e imagens. Esses elementos são organizados sob a aparência de um saber que diz algo sobre o estado da realidade. É essa totalidade significante que, em relação com a ação, encontra-se no centro da investigação científica. Atribuem-se a essa investigação as 
tarefas de descrevê-la, analisá-la e explicá-la em suas dimensões, formas, processos e funcionamentos (JODELET, 2001).

As pesquisas sobre as representações sociais da dengue constituem instrumentos teóricos que favorecem a compreensão das dinâmicas da doença segundo uma perspectiva ampla, englobando mecanismos psíquicos, culturais, históricos e simbólicos inerentes a um dado conjunto social. No entanto, essas pesquisas têm privilegiado as representaçóes da população e poucas têm se voltado para gestores e profissionais da saúde, ainda que estes sejam os responsáveis por elaborar e implementar as açóes de controle da doença. Quando se referem a territórios fronteiriços, os estudos são, ainda, mais escassos.

Conhecer as representaçôes sociais dos gestores e dos profissionais da saúde que atuam na fronteira sobre o controle da dengue pode contribuir para entender as dificuldades de implantação das políticas públicas de saúde neste contexto geográfico. Diante disso, a questão que se coloca é: quais são as representaçôes sociais dos gestores e profissionais da saúde sobre o enfrentamento da dengue em um município localizado em um espaço fronteiriço? Partindo dessa perspectiva, o presente estudo tem como objetivo identificar e analisar as representaçóes sociais dos gestores e profissionais da saúde sobre os desafios da prevenção e controle da dengue em Corumbá, Mato Grosso do Sul, fronteira Brasil/Bolívia.

\section{Metodologia}

Trata-se de um estudo qualitativo realizado no segundo semestre de 2016 no município de Corumbá, situado a oeste do estado de Mato Grosso do Sul, na fronteira do Brasil com a Bolívia.

O Brasil faz fronteira com a Bolívia por uma extensão de $3.423 \mathrm{~km}$, o que corresponde a $20 \%$ da linha divisória continental com os países vizinhos. A zona de fronteira formada pelos dois países engloba faixas fronteiriças pertencentes a quatro estados brasileiros (Acre, Rondônia, Mato Grosso e Mato Grosso do Sul) e três departamentos bolivianos (Pando, Beni e Santa Cruz) (BRASIL, 2005a). No estado de Mato Grosso do Sul (MS), na Região Centro-Oeste brasileira, o único município que possui contato territorial com a Bolívia é Corumbá, que se limita a oeste com duas seções municipais bolivianas da província Germán Busch, do departamento de Santa Cruz: Puerto Quijarro e Puerto Suárez. 
Com cerca de 160 mil habitantes, sendo aproximadamente 45 mil do lado boliviano, essa fronteira apresenta um fluxo transfronteiriço frequente, dinâmico e diverso (COSTA, 2013). De acordo com a Divisão de Controle de Imigração da Polícia Federal, em 2016 passaram pelo posto de migração de Corumbá 163.811 pessoas de várias nacionalidades (bolivianos, brasileiros, peruanos, paraguaios, israelenses etc). Esse contexto favorece a transmissão da dengue e impóe um importante desafio para gestores e profissionais da saúde locais.

É importante destacar que, para a compreensão das representaçôes sociais, a mediação privilegiada é a linguagem. Para Bakhtin (1986, p. 36), “a palavra é o modo mais puro e sensível de relação social”. Portanto, neste trabalho, os dados foram coletados através da técnica de entrevista, que é uma forma de interação social que valoriza o uso da palavra e permite o acesso às reflexôes dos entrevistados sobre a realidade que vivenciam (MINAYO, 2013). Utilizou-se um roteiro semiestruturado que contemplou informaçôes para caracterização dos participantes (sexo, idade, formação e experiência profissional e tipo de vínculo empregatício) e perguntas abertas relacionadas ao objetivo da pesquisa. Os questionamentos que nos permitiram o acesso às representaçôes elaboradas pelos sujeitos foram:

a) Fale da sua experiência em trabalhar com dengue em município de fronteira - dificuldades/facilidades encontradas.

b) Em sua opinião, a Secretaria Municipal de Saúde desenvolve açôes integradas de controle da dengue com o município do país vizinho? Você participa dessas açôes? Como são?

c) Existe um Comitê Binacional ativo?

d) Você sabe informar como é feita a troca de informações sobre a dengue com o município do país vizinho?

As entrevistas foram gravadas e transcritas na íntegra para posterior análise. Os sujeitos da pesquisa foram os gestores e os profissionais da saúde do município de Corumbá. No grupo dos gestores, foram selecionados para a pesquisa a secretária municipal de Saúde, a gerente da vigilância em saúde, a coordenadora da vigilância epidemiológica, a coordenadora de controle de vetores e a coordenadora da atenção primária à saúde. Os entrevistados foram escolhidos de forma intencional por serem informantes-chave, tendo como critério de inclusão a sua inserção e experiência 
enquanto profissionais componentes do processo de gestão, operacionalização e implantação das ações de controle da dengue no município de Corumbá.

Para o grupo dos profissionais da saúde, definiram-se como sujeitos da pesquisa os médicos e enfermeiros atuantes nas equipes Saúde da Família (ESF) e na Santa Casa de Misericórdia - hospital filantrópico conveniado com o SUS - do município de Corumbá. A escolha do grupo foi pautada na premissa de que esses profissionais são a referência no município na área de prevenção, controle e tratamento da dengue nos diferentes níveis de atenção à saúde.

À época da coleta de dados, Corumbá possuía 22 Unidades Básicas de Saúde da Família (UBSF) com 26 equipes implantadas (22 localizadas na zona urbana e quatro na rural). A amostra para esse grupo foi constituída de todos os médicos e enfermeiros das ESF urbanas que estavam presentes no local de trabalho no momento da pesquisa e que, voluntariamente, aceitaram a participar. As ESF da zona rural foram excluídas do estudo devido às dificuldades operacionais, distância e acesso.

Para a realização da pesquisa na Santa Casa de Misericórdia, foram abrangidas as especialidades e unidades que recebem pacientes com dengue: o pronto-socorro e o setor de leito de internação adulto e pediátrico. Foram convidados para participar do estudo um médico e um enfermeiro do período diurno e noturno, selecionados por meio de sorteio. Buscou-se contemplar dias úteis e fins de semana. Caso o profissional sorteado não aceitasse participar do estudo, outro sorteio seria realizado. Considerando que muitos profissionais atuavam nas ESF e nos hospitais, concomitantemente, foram excluídos aqueles que já haviam sido entrevistados.

Do total de 85 profissionais elegíveis para o estudo, foram entrevistados 68: cinco gestores, 13 médicos e 20 enfermeiros da ESF e 14 médicos e 16 enfermeiros da Santa Casa de Misericórdia de Corumbá.

Para a análise dos dados, empregou-se o método do Discurso do Sujeito Coletivo (DSC) (LEFÈVRE; LEFÈVRE, 2003) e software DSCsoft (versão aprimorada do Qualiquantisoft) desenvolvido na Faculdade de Saúde Pública da Universidade de São Paulo (USP) por Lefèvre e Lefèvre em parceria com Sales \& Paschoal Informática. O DSC é uma proposta de organização e tabulação de dados qualitativos de natureza verbal, obtidos de depoimentos. O procedimento metodológico básico exige que se identifiquem nos depoimentos dos entrevistados as ideias centrais a 
respeito da questáo estabelecida. O discurso dos entrevistados pode conter uma ou mais ideias centrais. Para cada ideia central formada são atribuídas expressões-chave e agrupadas pelo sentido semelhante em categorias de respostas. Com o material das expressóes-chave das ideias centrais constroem-se discursos-síntese, na primeira pessoa do singular, que são os DSCs (LEFÈVRE; LEFÈVRE, 2003; 2012).

O projeto de pesquisa foi aprovado pelo Comitê de Ética vinculado à Universidade Federal de Mato Grosso do Sul, sob o protocolo número 1.804.168, atendendo às Diretrizes e Normas de Pesquisa estabelecidas pela Resolução no. 466/12, do Conselho Nacional de Saúde.

\section{Resultados e discussão}

A idade dos entrevistados variou de 25 a 65 anos, com média de 39,6 anos. A maioria era do sexo feminino $(75 \%)$, e um pouco mais da metade $(57,3 \%)$ era servidora pública concursada (tabela 1 ).

$\mathrm{Na}$ análise dos DSC formados a partir das respostas dos gestores, profissionais de saúde da ESF e da Santa Casa de Misericórdia às questôes do estudo, identificaramse quatro ideias centrais (tabela 2).

Observa-se que, na percepção dos gestores e profissionais, a insuficiência de recursos financeiros é a maior dificuldade encontrada por Corumbá no combate à dengue. Houve 67,4\% (n=46) de citaçôes dessas expressôes-chave pelos entrevistados. É uma representação de grande intensidade e alta amplitude, pois é fortemente compartilhada por todo o campo analisado (tabela 2). 


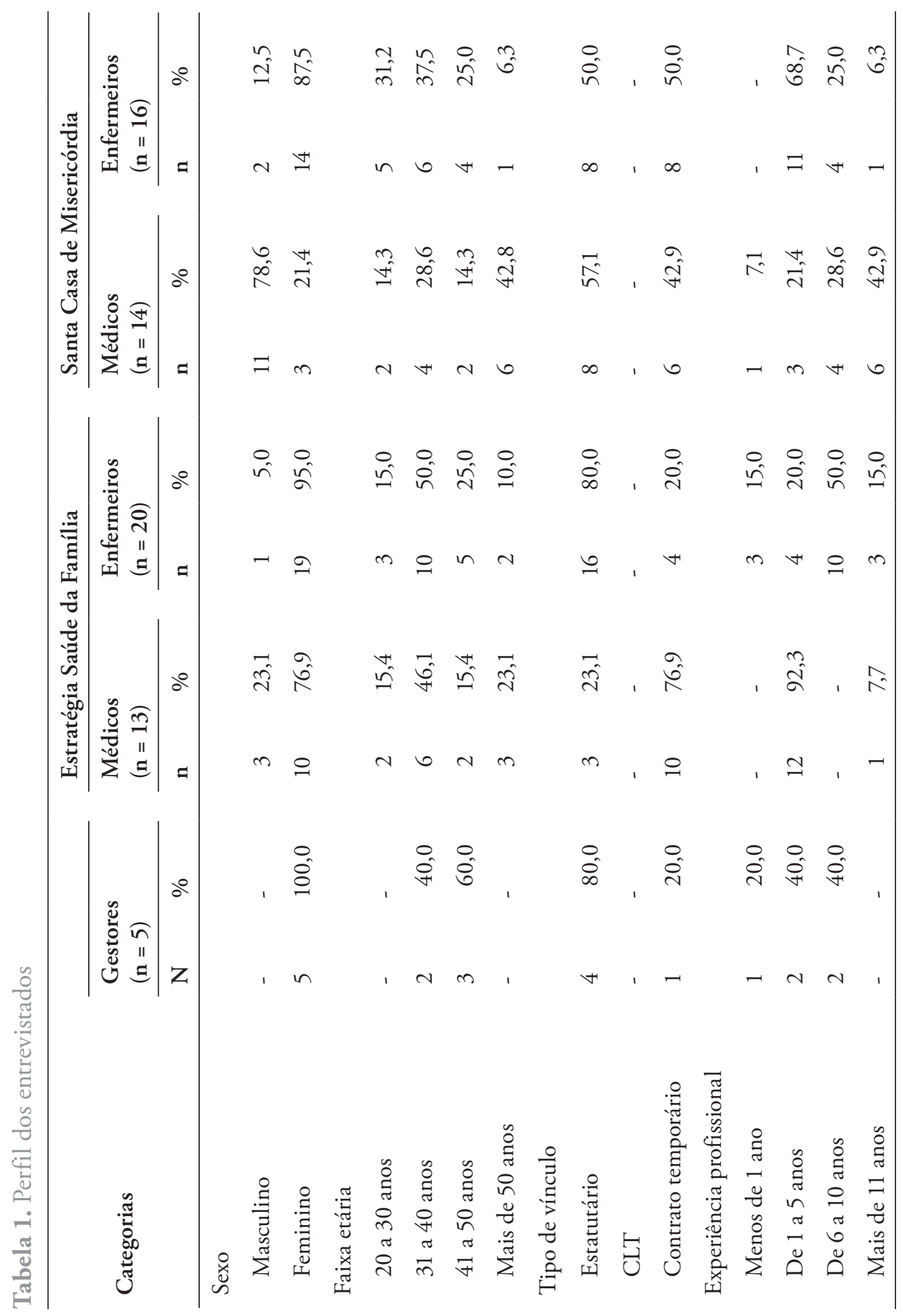


| Página 8 de 21

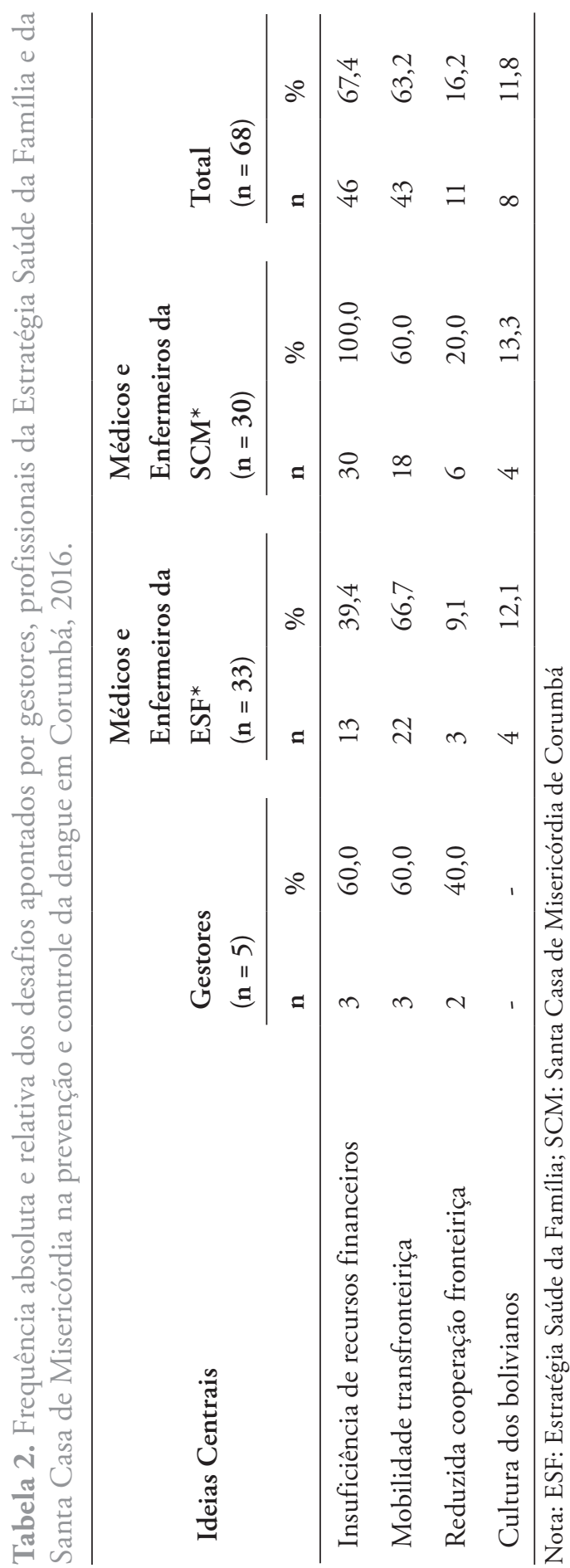




\title{
DSC 1 - Insuficiência de recursos financeiros
}

\begin{abstract}
A maior dificuldade é o orçamento. Nós temos muitos gastos com o país vizinho. Nós temos um único hospital para atender Corumbá, Ladário e Bolívia. Então, tudo que a gente tem, tem que dividir com eles. Nós recebemos vários pacientes vindo do entorno de Santa Cruz com dengue hemorrágica e a gente não tem como recusar o atendimento. Tudo bem que são pessoas, mas ocupam os leitos e acabam dificultando o atendimento aos próprios brasileiros. Sobrecarrega nosso sistema. Nosso SUS abraça todo mundo, porém os recursos nem sempre vêm nessa amplitude. Os bolivianos aprenderam que aqui eles não pagam nada, porque lá na Bolívia o sistema de saúde não é público. Então eles vêm pra Corumbá. Não é o caso de não atendermos, mas sim de termos condiçóes de atendê-los. Com a prevenção, é a mesma coisa. Os bolivianos não têm estrutura nenhuma. Eles não têm agentes de saúde, não têm agentes de vetores, não têm controle da dengue. Muitas vezes, a gente tem que ir lá para ajudá-los a combater o mosquito, não por bondade, mas para evitar que a doença chegue aqui. Eu vejo a necessidade de um recurso financeiro específico para a área de fronteira. Tem que ser diferenciado, não pode ser igual a todos. O Ministério da Saúde tem que fortalecer essa política de fronteira para que possam vir mais recursos.
\end{abstract}

A partir do DSC 1, é possível identificar que a insuficiência de recursos financeiros está diretamente relacionada ao fato de Corumbá ser município de fronteira. Para os entrevistados, a busca por atendimento pelos bolivianos é uma realidade nos serviços de saúde do município. Como consequência, tem-se uma pressáo sobre os serviços ofertados e os recursos não são suficientes para atender a todos.

Nas fronteiras, a população circula de um país a outro na tentativa de suprir suas necessidades e aproveitar oportunidades (PEITER, 2007). Esse dinamismo manifesta-se com maior frequência na área da saúde, principalmente quando coexistem sistemas de saúde assimétricos, a exemplo do Brasil e da Bolívia. O município de Corumbá se caracteriza como um polo de atração para os moradores dos municípios bolivianos vizinhos, em função da gratuidade e da qualidade dos serviços de saúde (MARQUES, 2012).

Segundo Gadelha e Costa (2007), o provimento das políticas de saúde nos municípios de fronteira do Brasil fica comprometido em razão da população flutuante que utiliza o sistema náo ser contabilizada para fins de repasse financeiro do governo federal. Os recursos recebidos pelos municípios para financiar os procedimentos e açôes de saúde são baseados na estimativa da população municipal. Consequentemente, os municípios fronteiriços não dispóem de orçamento para assumir toda a demanda de brasileiros não residentes no país e tampouco de estrangeiros fronteiriços, situação essa apontada pelos secretários de Saúde dessas 
localidades como a maior dificuldade para a gestâo do Sistema Único de Saúde (SUS) (GIOVANELLA et al., 2007).

Apesar de não existir no município um sistema que permita a quantificação e qualificação do atendimento ao estrangeiro (FERREIRA; MARIANI; BRATICEVIC, 2015), a expressão "nós recebemos vários pacientes vindos do entorno de Santa Cruz com dengue hemorrágica" aparece para demonstrar que a Santa Casa de Misericórdia de Corumbá, o único hospital da região, atende bolivianos com essa enfermidade e esse atendimento gera um custo. Um estudo multicêntrico desenvolvido em quatro regióes brasileiras demonstrou que cada paciente hospitalizado por dengue custa para o SUS entre US\$ 238 e 479 (MARTELLI et al., 2015).

No imaginário dos entrevistados, além dos gastos com assistência ao paciente boliviano com dengue, Corumbá, como forma de evitar ou controlar as epidemias, desenvolve açóes de combate ao mosquito Aedes aegypti nos municípios bolivianos vizinhos.

Fonseca (2011), em sua dissertação de mestrado, listou várias ações de combate ao mosquito que são desenvolvidas pela Secretaria Municipal de Saúde de Corumbá no país vizinho: levantamento rápido do índice de infestação por Aedes aegypti (LIRAa), identificação larval, borrifação com fumacê e ações educativas. No entanto, a autora frisa que são ações pontuais, sem periodicidade e que não estão inseridas na rotina de trabalho.

Embora sejam ações pontuais, conforme mencionado, elas implicam a utilização de recursos próprios. É importante destacar que o financiamento das açóes de combate ao vetor da dengue é realizado por meio do Piso Fixo de Vigilância em Saúde, cujo repasse da verba é efetuado mensalmente pelo Ministério da Saúde a estados e municípios e, também, tem como base de cálculo o tamanho da população local (BRASIL, 2007). Assim sendo, Corumbá não recebe verba extra para a realização dessas atividades, onerando o orçamento do município.

Como estratégia para superar a insuficiência de recursos financeiros, o DSC aponta a necessidade de um olhar diferenciado por parte do Governo Federal para os municípios de fronteira. Convém observar que a iniciativa do Ministério da Saúde do Brasil para amenizar essa situação foi a criação, em 2005, do Sistema Integrado de Saúde das Fronteiras (SIS-Fronteiras), cujo objetivo era promover a integração de açôes e serviços de saúde na região de fronteiras e contribuir para a organização e fortalecimento dos sistemas locais de saúde (BRASIL, 2005b). 
Sobre a implementação do SIS-Fronteiras em Corumbá, o estudo conduzido por Ferreira, Mariani e Braticevic (2015) revelou que os objetivos iniciais do programa não foram atingidos. Sua operacionalização ficou restrita a uma pontual ampliação de repasse financeiro verticalizado para o município, desprovido de parâmetros de controle e avaliação. De modo similar, um estudo desenvolvido nas cidades gêmeas da linha de fronteira entre Brasil e Argentina, Paraguai e Uruguai também confirmou a distância entre o pretendido e o alcançado pelo SIS-Fronteiras em termos de operacionalização e elementos de integração previstos; igualmente não se concretizaram (NOGUEIRA; FAGUNDES, 2014). Os autores argumentam que nem mesmo se identificaram quaisquer iniciativas nesse sentido.

Diante dessa realidade, expressóes como "a gente não tem como recusar o atendimento", "tudo bem que são pessoas", "não é o caso de não atendermos" presentes no DSC revelam o dilema ético-profissional com que os gestores locais e profissionais da saúde se deparam rotineiramente. Precisam, ante a insuficiência de recursos financeiros para atender à demanda local, não deixar de atender o estrangeiro e, tampouco, de auxiliar o país vizinho no combate ao vetor da dengue. Vale lembrar que a Constituição da República Federativa do Brasil garante o acesso universal e igualitário às açôes e serviços de saúde para sua promoção, proteção e recuperaçấo a todo ser humano.

\section{DSC 2 - Mobilidade transfronteiriça}

A maior dificuldade é essa fronteira aberta. Você vê gente entrando por todos os lados. Todos entram. Entram as pessoas doentes e até mesmo os vetores das doenças. Aqui também é a porta de entrada para o Brasil e também temos pessoas de várias nacionalidades passando por aqui e é mais difícil de chegar neles, é uma população flutuante. O fluxo é muito grande. Antigamente, nós tínhamos a feirinha Bras-Bol e todos os anos tínhamos focos de dengue naquela região próxima. A Bolívia é uma área endêmica também pra dengue e, por ser muito fácil atravessar a fronteira, as pessoas doentes acabam circulando livremente aqui. Elas procuram atendimento, são diagnosticadas com dengue e somem. Você fica sem saber onde ela pegou a doença, onde é o foco. Não temos como fazer bloqueio dos casos e até mesmo acompanhar esse paciente. A gente não consegue achar essas pessoas. Elas vão e vêm quando querem.

Segundo esse DSC, o controle da dengue no município de Corumbá é dificultado pela mobilidade transfronteiriça. Benedetti (2011) destaca que existe uma relação dialética entre fronteira e mobilidade, tanto que "los lugares de frontera atraen movilidades y las movilidades dan vida a esas localizaciones". 
A mobilidade é um movimento incerto, por períodos curtos, dias ou menos de uma semana, no qual as pessoas retornam constantemente para seu lugar de origem (TAPIA; PARELLA, 2015). Nos espaços fronteiriços é comum esse tipo de fluxo com distintas finalidades: atravessar a fronteira por trabalho, atendimento médico, estudos, lazer ou para comprar mais barato, e sua intensidade depende do tipo de acesso que se tem, da infraestrutura, e da proximidade entre as cidades fronteiriças.

Para a vigilância em saúde, a mobilidade transfronteiriça é vista como uma ameaça ou risco. $\mathrm{Na}$ epidemiologia das infecçôes por dengue, ela desempenha um papel essencial, uma vez que os indivíduos podem transportar os diversos sorotipos e cepas do vírus para áreas que podem sustentar a transmissão (WHO, 2009). Esse quadro pode ser observado na epidemia de dengue ocorrida em Corumbá, no ano de 2009, causada pelo vírus tipo 1, que havia dez anos não era detectado no estado de Mato Grosso do Sul. De acordo com a Secretaria Municipal de Saúde, o primeiro caso registrado no município veio de Santa Cruz de la Sierra, região com ambiente propício para a propagação do vírus (FONSECA, 2011).

Outras implicaçóes explicitadas no DSC, em razão dos fluxos transfronteiriços, foram as dificuldades para realização do bloqueio dos casos de dengue e para o acompanhamento do tratamento dos pacientes. Essas açôes de saúde são prejudicadas, em boa parte, pelas estratégias adotadas pelos estrangeiros e brasileiros não residentes no país para serem atendidos no SUS. O empréstimo de endereço de parentes e o aluguel de casas temporárias no Brasil são algumas das táticas mais comuns empregadas por eles.

A análise quantitativa dessa representação demonstra que é possuidora de grande intensidade e alta amplitude. Está presente na fala de 63,2\% (n=43) dos entrevistados e é fortemente compartilhada por todos os entrevistados.

\section{DSC 3 - Reduzida cooperação fronteiriça}

São dois países diferentes, com condutas e normativas diferentes. Nós não temos autonomia para atuar do outro lado da fronteira. A gente náo pode entrar na casa do vizinho. Lá é outra legislação. É tudo diferente. A gente encontra barreiras de fazer o trabalho. As ações que a gente faz aqui não são as que eles fazem lá. A questấo é política. Depende muito dos gestores. Se a gente tem um gestor que entende a importância de se trabalhar em conjunto com a Bolívia, as coisas fluem. Caso contrário, não. Tem que ter um calendário único para as ações de saúde. Pra dengue tem que ter um sistema único de informação entre essas cidades. A gente tem que ter acesso aos números de lá e eles aos nossos. 
O DSC demonstra as dificuldades de se trabalhar a prevenção e o controle de doenças, como a dengue, nos municípios fronteiriços. A questão escapa da competência das equipes de vigilância em saúde, pois sua atuação é restrita aos limites territoriais.

As fronteiras são constituídas de, pelo menos, dois territórios com normas particulares (COSTA, 2013). Importante lembrar que é na fronteira onde os interesses nacionais e locais confluem para o mesmo território e onde ocorre uma justaposição de escalas (BENEDETTI, 2011). Isso porque a mesma linha que limita os territórios dos países (nesse caso Brasil e Bolívia) serve para delimitar os territórios dos municípios (Corumbá e Puerto Quijarro). Essa forma de pensar vai ao encontro de Gallo, Costa e Moraes (2004, p. 43) ao reconhecerem que "cuando el municipio vecino es también de país vecino, barreras diplomáticas, legales, económicas y sociales se interponen a la planificación conjunta".

Com efeito, além de jurídicas, as dificuldades de enfrentamento do controle da dengue também são políticas, como se mostra evidente no DSC. Apesar da proximidade geográfica, as gestôes territoriais dessas localidades não podem executar acordos formais, já que estes são prerrogativas dos governos federais, cujos centros decisórios estão distantes. Conforme as diretrizes para o desenvolvimento da cooperação técnica internacional multilateral e bilateral, editadas pela Agência Brasileira de Cooperação (ABC), "somente a União tem competência para assinar acordos internacionais de cooperação técnica” (BRASIL, 2014, p. 14). O documento assinala, ainda, que, em caso de interesse de Estados e Municípios em estabelecer parceria para cooperação técnica com organismos ou governos de outros países, "a iniciativa deverá, necessariamente, ser tramitada por intermédio da $A B C$, desde que existindo um Acordo Básico em vigor entre o Brasil e o ente cooperante externo" (BRASIL, 2014, p. 14).

Por outro lado, embora caiba à Uniáo a última palavra no que concerne aos acordos internacionais, é inegável que a atuação de governos subnacionais possa dar legitimidade a instrumentos de decisão em nível regional, reduzindo desigualdades sociais e assimetrias entre países (GIOVANELLA et al., 2007).

A cooperação entre os dois municípios de fronteira para se trabalhar a problemática da dengue aparece no DSC como dependente dos interesses dos gestores em exercício. Como observa Nascimento (2016), as alternâncias de governo podem ou não priorizar os assuntos internacionais na sua agenda. Ainda de acordo 
com a autora, esse é um dos maiores desafios para o fortalecimento das práticas de cooperação entre os países da América do Sul.

A questão é que o enfrentamento das doenças em municípios fronteiriços só é possível mediante a cooperação entre eles (PEITER, 2007; GIOVANELLA et al., 2007). É necessário que as açôes preventivas e de controle de vetores sejam pactuadas e executadas de forma simultânea em ambos os lados da fronteira para efetiva eficácia. Por isso o DSC é categórico: "Tem que ter um calendário único para as ações de saúde”. Misoczky et al. (2004) encontraram resultados idênticos ao entrevistarem profissionais de saúde do município de Aceguá (RS), na fronteira entre Brasil e Uruguai, para os quais a população fronteiriça, do ponto de vista epidemiológico, deve ser considerada como uma, em vez de populaçôes diferentes em dois lados de uma fronteira.

Os entrevistados ressaltam, ainda, como relevante para o controle da dengue em Corumbá a necessidade de um sistema de informaçóes compartilhado com os municípios fronteiriços da Bolívia. Um estudo realizado com técnicos do sistema de vigilância da fronteira do Brasil com os países do Cone Sul e da fronteira dos Estados Unidos da América com o México revelou, de modo similar, a valorização do intercâmbio de informaçôes entre países como um dos fatores de maior importância para a vigilância epidemiológica de fronteiras (OLIVEIRA, 2015). A mesma pesquisa relata que o intercâmbio de informação entre os países ocorre em mais de $80 \%$ das jurisdiçôes norte-americanas e em $71 \%$ das brasileiras. No entanto, a oportunidade, qualidade e completitude das informaçôes intercambiadas foram consideradas, na escala utilizada, de média a fraca.

A intensidade dessa representação é de 16,2\% ( $n=11)$, ou seja, essa é uma representação de menor força em relação às duas anteriores. Entretanto, possui alta amplitude por ser encontrada em diversos segmentos do campo social (tabela 2).

\section{DSC 4 - Cultura dos bolivianos}

A cultura dos bolivianos é diferente. Aqui existe muito boliviano, por exemplo, no bairro Aeroporto, eles tomaram conta, compraram várias casinhas. A questâo da limpeza, da higiene pessoal e da casa não é igual à nossa. Os bolivianos tomaram conta de Corumbá e é difícil de lidar com eles porque eles têm muitos depósitos de lixo e isso prejudica o combate ao vetor. É cultural mesmo! Lá na Bolívia eles não têm cuidado com o saneamento básico e com nada que diz respeito à higiene. É a cultura deles e eles estão inseridos aqui com a gente. 
Os entrevistados também apontaram a cultura dos bolivianos como uma das principais dificuldades no combate à dengue em Corumbá. Para eles, os bolivianos moram e transitam em Corumbá reproduzindo os hábitos e costumes de suas origens. Acreditam que suas práticas cotidianas são resultantes das estratégias de sobrevivência num meio ausente de elementos mínimos de saneamento básico. Acostumados a um ambiente com grandes adversidades, replicam em Corumbá os costumes adquiridos, tanto como moradores, como trabalhadores (migrantes pendulares).

A cultura, nesse sentido e conforme caracterizada por Claval (2002), é percebida pelos entrevistados como um conjunto de atitudes e de costumes imutáveis que identificam determinado grupo social. Contudo, nos tempos mais atuais, a cultura vem sendo compreendida como multitemporal, dinâmica e, portanto, mutável. E cada vez mais estudos vêm mostrando a presença do hibridismo cultural (GARCÍA CANCLINI, 2006).

As fronteiras são marcos simbólicos constituídos pelo imaginário, forjando as representaçóes coletivas que vão dar significados ao real percebido, atribuindolhes os valores e as formas de condutas (CARDIA, 2009). O estranhamento é próprio do fronteiriço - é da sua condição de viver na borda - e é proporcional ao distanciamento entre as realidades vividas e as regras de grupos (CARDIA, 2009). Corumbá é o centro econômico regional da fronteira. Possui o setor terciário mais diversificado e complexo. Além disso, os sistemas de saúde presentes na fronteira são completamente diferentes: o brasileiro é público e o boliviano, privado (MARQUES, 2012). Esses elementos corroboram para explicar o estranhamento dos entrevistados frente aos bolivianos.

A culpabilização dos bolivianos pelas dificuldades de enfrentamento da dengue não encontra na cultura sua real motivação. Ferreira, Mariani e Braticevic (2015), analisando o discurso de dez profissionais de saúde atuantes em Corumbá, apresentam outra argumentaçáo. Para eles, os discursos são motivados pela forma de percepção do atendimento ao separar os usuários do Sistema Único de Saúde (SUS) em brasileiros e bolivianos. Com isso, a identidade pátria é reforçada como hegemônica e a percepção do "outro" reflete o imaginário particular da população brasileira da fronteira Brasil-Bolívia. Os profissionais de saúde incorporam o discurso de que os bolivianos são associados ao atraso e à pobreza, por conseguinte, ao binômio sujeira/doença. 
De fato, não existe uma relação entre a cultura dos bolivianos e as dificuldades de enfrentamento da dengue. Costa e Dias (2015), estudando as características das moradias dos bolivianos em Corumbá, revelam que elas guardam alguns traços muito singelos das memórias do solo pátrio, mas na paisagem não se diferenciam em nada das moradias dos corumbaenses. No estudo são indicados vários elementos da hibridação cultural entre brasileiros e bolivianos.

Um estudo comparativo em 2012 - tendo por base o LIRAa feito pela Secretaria Municipal de Saúde de Corumbá na própria cidade e nas áreas urbanas fronteiriças da Bolívia - demonstrou que não existem grandes diferenças em relação aos principais focos do Aedes aegypti. Os resultados demonstraram que a reprodução das larvas do mosquito tiveram como reservatórios dominantes o tipo A2 (depósito ao nível do solo) em Corumbá, no distrito Arroyo Concepción e na cidade de Puerto Suárez, relacionados aos problemas de abastecimento de água (armazenamento para uso doméstico). Apenas a cidade de Puerto Quijarro apresentou o reservatório dominante D1 (pneus e outros materiais rodantes) (AMETLLA; COSTA; COSTA, 2012).

Isso reforça o pensamento de que as respostas dos entrevistados foram influenciadas pelas suas práticas cotidianas de atendimento na rede pública de saúde, conforme observado por Ferreira, Mariani e Braticevic (2015). O que é considerado para os profissionais de saúde, subjetivamente, é o atendimento realizado e, neste caso, os bolivianos representam um problema, pois eles não contam para o Sistema. Nesse sentido, os profissionais internalizam no seu imaginário o discurso reproduzido pela maioria da sociedade local, que reforça a alteridade nacional em relação ao país vizinho, culpabilizando a cultura do outro.

Essa representação aparece em 11,8\% ( $\mathrm{n}=8)$ das falas dos sujeitos, porém é encontrada apenas nas falas dos profissionais de saúde. Foi a representação que apresentou menor intensidade em relação às outras e baixa amplitude, ou seja, é uma representação que não aparece nas falas de todo o campo pesquisado (tabela 2).

\section{Considerações finais}

As representaçôes sociais dos gestores e profissionais da saúde de Corumbá sobre o enfrentamento da dengue retratam os mesmos dilemas do planejamento e da oferta dos serviços de saúde em áreas de fronteira com relevantes assimetrias econômicas, sociais e de infraestruturas. O descompasso entre a contabilização oficial da 
população e as práticas cotidianas fronteiriças impóe sérias restriçôes orçamentárias para operacionalização da saúde. Este contexto resulta em dificuldades para a gestão local, com reflexos no atendimento dos profissionais da saúde e na demanda dos usuários brasileiros ou fronteiriços.

O discurso do sujeito coletivo reproduziu as particularidades do combate à dengue na franja fronteiriça estudada, mas carrega elementos comuns que podem ser aplicados ao enfrentamento de quaisquer doenças infectocontagiosas nas fronteiras com macrocaracterísticas semelhantes.

Em tempos de globalização, a mobilidade humana tem se intensificado cada vez mais. As passagens de fronteira são as portas de entrada e saída, tanto para os fluxos com amplitude nacional, como regional e fronteiriça. Logo, a intensidade dos fluxos fronteiriços não é uma anomalia do sistema. Cabe aos gestores da saúde (em suas múltiplas esferas) realizar a leitura e o entendimento da magnitude desses fluxos para adequação dos recursos e dos serviços necessários ao pleno atendimento da população.

A pesquisa demonstrou, ainda, que não é possível fazer a gestão e o atendimento em saúde nas fronteiras sem a cooperação e o compartilhamento de informaçôes entre os vizinhos. Em que pese a existência de iniciativas e de instrumentos para cooperação fronteiriça bilateral ou multilateral, as práticas ainda são intermitentes e fortemente personalizadas. Neste sentido, o estudo apresenta elementos que podem contribuir para melhoria da gestão da saúde em territórios fronteiriços e do atendimento de seus habitantes. ${ }^{1}$

\section{Referências}

ALVES, A. C. et al. Knowledge and practices related to dengue and its vector: a communitybased study from Southeast Brazil. Revista da Sociedade Brasileira de Medicina Tropical, v. 49, n. 2, p. 222-226, 2016.

AMETLlA, V. C.; COSTA, E. M. S.; COSTA, E. A. Vigilância epidemiológica da dengue na fronteira Brasil-Bolívia. In: XVII ENCONTRO NACIONAL DE GEÓGRAFOS. Anais... Belo Horizonte: AGB, 2012. p. 1-8.

BAKHTIN, M. Marxismo e filosofia da linguagem. São Paulo: Hucitec, 1986.

BENEDETTI, A. G. Lugares de frontera y movilidades comerciales en el sur sudamericano: una aproximación multiescalar. In: COSTA, E. A.; COSTA, G. V. L.; OLIVEIRA, M. M. M. Fronteiras em foco. Campo Grande: Ed. UFMS, 2011. p. 33-55. 
BHATT, S. et al. The global distribution and burden of dengue. Nature, v. 496, n. 7446, p. 504-507, 2013.

BRASIL. Ministério da Integração Nacional. Secretaria de Programas Regionais. Programa de Desenvolvimento da Faixa de Fronteira. Proposta de Reestruturação do Programa de Desenvolvimento da Faixa de Fronteira. Brasília: Ministério da Integração Nacional, 2005a.

- Ministério da Saúde. Portaria No 204, de 29 de janeiro de 2007. Regulamenta o financiamento e a transferência dos recursos federais para as açôes e os serviços de saúde, na forma de blocos de financiamento, com o respectivo monitoramento e controle. Brasília: Ministério da Saúde; Gabinete do Ministro, 2007.

. Ministério da Saúde. Secretaria de Vigilância em Saúde. Boletim Epidemiológico, v. 49, n. 2, 2018. Brasília: Ministério da Saúde, 2018.

. Ministério da Saúde. Secretaria de Vigilância em Saúde. Situação Epidemiológica/ Dados. Casos de dengue: Brasil, Grandes Regiôes e Unidades Federadas, 1990 a 2016. Brasília: Ministério da Saúde, 2017. Disponível em: <http://u.saude.gov.br/index.php/situacaoepidemiologica-dados-dengue>. Acesso em: 11 fev. 2018.

- Ministério da Saúde. Sistema Integrado de Saúde das Fronteiras: SIS Fronteiras e a Integração em Busca da Equidade. Brasília: Secretaria Executiva, Sistema Integrado de Saúde das Fronteiras, 2005b.

- Ministério das Relações Exteriores. Agência Brasileira de Cooperação. Diretrizes para o desenvolvimento da cooperação técnica internacional multilateral e bilateral. 4.ed. Brasília: Agência Brasileira de Cooperação, 2014.

CARDIA, L. M. Espaços e culturas de fronteira na Amazônia ocidental. Ateliê Geográfico, Goiânia-GO, v. 3, n. 7, 2009, p. 108-125.

CARMONA, G.; DONAIRES, L. F. Percepciones comunitarias relativas a la prevención del dengue en asentamientos humanos afectados. Interface - Comunicação, Saúde, Educação, v. 20, n. 59, p. 839-52, 2016.

CLAVAL, P. A volta do cultural na geografia. Mercator, ano 1, n. 1, p. 19-28, 2002.

COSTA, E. A. Mobilidade e fronteira: as territorialidades dos jovens de Corumbá, Brasil. Revista Transporte y Territorio, v. 9, p. 71-93, 2013.

COSTA, E. A.; DIAS, R. T. R. Lugar e territorialidades dos bolivianos em Corumbá-MS. Cadernos de Estudos Culturais, v. 7, p. 33-46, 2015.

FERREIRA, C. M. P. G.; MARIANI, M. A. P.; BRATICEVIC, S. I. As múltiplas fronteiras presentes no atendimento à saúde do estrangeiro em Corumbá, Brasil. Saúde e Sociedade, São Paulo, v. 24, n. 4, p. 1137-1150, 2015. 
FONSECA, B. O. As politicas públicas de vigilância em saúde na fronteira Brasil-Bolivia. 2011. 59f. Dissertação. (Mestrado em Estudos Fronteiriços) - Campus do Pantanal, Universidade Federal de Mato Grosso do Sul, Corumbá-MS, 2011.

GADELHA, C. A. G.; COSTA, L. Integração de fronteiras: a saúde no contexto de uma política nacional de desenvolvimento. Cadernos de Saúde Pública. Rio de Janeiro, v. 23, supl 2, p. S237-S250, 2007.

GALLO, E.; COSTA, L.; MORAES, A. La integración de los sistemas de salud que atienden a la población fronteriza de los países del Mercosur - SIS-Mercosur. In: GALLO, E.; COSTA, L. (Orgs.). Sistema integrado de salud del Mercosur / SIS - Mercosur. Una agenda para integración. Brasilia: OPAS, 2004. p. 41-54.

GARCÍA-CANCLINI, N. Culturas híbridas: estratégias para entrar e sair da modernidade. 4.ed. São Paulo: Editora da Universidade de São Paulo, 2006.

GIOVANELLA, L. et al. Saúde nas fronteiras: acesso e demandas de estrangeiros e brasileiros não residentes ao SUS nas cidades de fronteira com países do Mercosul na perspectiva dos secretários municipais de saúde. Cadernos de Saúde Pública, Rio de Janeiro, v. 23, supl.2, p. S251-S266, 2007.

JODELET, D. Representaçôes sociais: um domínio em expansão. In. . (Org.). As representaçôes sociais. Rio de Janeiro: Ed. UERJ, 2001. p. 17-44.

LEFÈVRE, F.; LEFÈVRE, A. M. C. O discurso do sujeito coletivo: um novo enfoque em pesquisa qualitativa (desdobramentos). Caxias do Sul: EDUCS, 2003.

- Pesquisa de representação social: um enfoque qualiquantitativo: a metodologia do Discurso do Sujeito Coletivo. 2.ed. Brasília: Liber Livro, 2012.

MARQUES, A. M. Mobilidade, acesso à saúde e espaço de fronteira: o caso de Corumbá-MS, Puerto Quijarro e Puerto Suárez-Bolivia. 2012. 174 f. Tese. (Doutorado em Demografia) Universidade Estadual de Campinas, Campinas, 2012.

MARTELLI, C. M. T. et al. Economic impact of dengue: multicenter study across four Brazilian Regions. PLOS Neglected Tropical Diseases, v. 9, n. 9, p. 1-19, 2015.

MINAYO, M. C. S. O desafio do conhecimento: pesquisa qualitativa em saúde. 13.ed. São Paulo: Hucitec, 2013.

MISOCZKY, M. C. et al. Gestão da atenção à saúde em territórios de fronteiras: algumas constataçôes a partir de casos do estado do Rio Grande do Sul. In. MISOCZKY, M. C.; BORDIN, R. (Orgs.). Gestão local em saúde: práticas e reflexões. Porto Alegre: Dacasa, 2004. p. 9-34.

MOSCOVICI, S. Representación social. In: FORGAS, J. P. (Ed.). Social Cognition perspectives on everyday knowledge. London: Academic Press, 1981. p.181-209. 
NASCIMENTO, R. F. O Projeto Mato Grosso do Sul Sem Fronteiras e a paradiplomacia transfronteiriça entre Brasil, Bolivia e Paraguai. 2016. 80f. Dissertação. (Mestrado em Estudos Fronteiriços) - Campus do Pantanal, Universidade Federal de Mato Grosso do Sul, Corumbá, MS, 2016.

NOGUEIRA, V. M. R.; FAGUNDES, H. S. A implementação do SIS Fronteiras - Perspectivas para a ampliação do direito à saúde na fronteira Arco Sul. Serviço Social e Saúde. Campinas, v. 13, n. 2, p. 245-260, 2014.

OLIVEIRA, R. B. Vigilância epidemiológica de fronteiras terrestres do Arco Sul do Brasil. 2015. 135f. Tese. (Doutorado em Ciências) - Escola Nacional de Saúde Pública Sergio Arouca, Rio de Janeiro, 2015.

PEITER, P. C. Condiciones de vida, situación de la salud y disponibilidad de servicios de salud en la frontera de Brasil: un enfoque geográfico. Cadernos de Saúde Pública. Rio de Janeiro, v. 23, supl. 2, p. S237-S250, 2007.

REIS, C. B.; ANDRADE, S. M. O.; CUNHA, R. V. Aliados do A. aegypti: fatores contribuintes para a ocorrência do Dengue segundo as representaçôes sociais dos profissionais das equipes de saúde da família. Ciência e Saúde Coletiva. Rio de Janeiro, v. 18, n. 2, p. 517-26, 2013.

SANTOS, S. L.; CABRAL, A. C. S. P.; AUGUSTO, L. G. S. Conhecimento, atitude e prática sobre dengue, seu vetor e açóes de controle em uma comunidade urbana do Nordeste. Ciência e Saúde Coletiva. Rio de Janeiro, v. 16, Supl. 1, p. 1319-1330, 2011.

SCHATZMAYR, H. G. Dengue situation by year 2000. Memórias do Instituto Oswaldo Cruz. Rio de Janeiro, v. 95, supl. I, p. 179-181, 2000.

TAPIA, M.; PARELLA, S. Las regiones fronterizas para el estudio de la migración y la circulación. Un análisis de dos casos ilustrativos. In: GUIZARDI, M. Las regiones fronterizas para el estudio de la migración y la circulación. Un análisis de dos casos ilustrativos. Santiago de Chile: Ocho Libros, 2015. p. 173-206.

WORLD HEALTH ORGANIZATION. Dengue: guidelines for diagnosis, treatment, prevention and control. New edition. Geneva: WHO, 2009.

. Number of reported cases of dengue and severe dengue (SD) in the Americas, by Country. Epidemiological Week 52, Feb. 6. Geneva: WHO, 2017.

\section{Nota}

${ }^{1}$ E. M. da S. Costa trabalhou em todas as etapas de elaboração do artigo. E. A da Costa colaborou na concepção; análise e interpretação dos dados; redação do artigo, discussão dos resultados e aprovação da versão final. R. V. da Cunha participou da concepção, revisão crítica e aprovação da versão final a ser publicada. 


\section{Abstract}

Challenges of the prevention and control of dengue fever in Brazil/Bolivia border: social representations of health managers and professionals

This study aims to identify and analyze the social representations of health managers and professionals on challenges of combating dengue fever in Corumba, Mato Grosso do Sul state, Brazil/Bolivia border. It is a qualitative research based on the theory of social representations. For data collection were interviewed five managers and 63 health professionals active in the Family Health Strategy and Santa Casa de Misericordia, whose content analysis was done using the Collective Subject Discourse technique. The results indicate that the municipality has great difficulties to combat dengue fever because it is a border. In the discourse analysis, four main ideas were identified: insufficient financial resources, cross-border mobility, border cooperation reduced and Bolivian culture. The study reinforces the need for bilateral or multilateral cooperation for better health care in border areas.

Keywords: dengue; prevention and control; border areas; health staff; heath manager. 